\title{
Nota prévia sobre Rutaceae nova da Amazônia
}

\author{
Byron W. P. De Alburquerque (*) \\ Mário HoNDA (*)
}

Consultando material do Herbário do Instituto Nacional de Pesquisas da Amazônia (INPA), deparamos com um espécime recentemente coletado no $\mathrm{Km} 155$ da. Estrada Manaus-Itacoatiara, cujos caracteres morfológicos não se ajustam com os das demais espécies do gênero Fagara, motivando considerálo como espécie nova para, a ciência .

Neste trabalho apresentamos as características principais desta espécie, bem como a descrição macroscópica da madeira. Em outra oportunidade publicaremos sua diagnoss e descrição macro e microscópica da madeica, acompanhadas das figuras respectivas.

Fagara Machadoi Albuq., n. sp.

Arbor $30 \mathrm{~m}$ alta; diam. circa $45 \mathrm{~cm}$; caule ramoso; foliis alternis, paripinnatis; petiolis atque petiolulis velutinis; petiolulis basi articulatis; foliolis magnis, oblongo-ellipticis, alternis vel oppositis, coriaceis, subtus velutinis, apice a.cuminatis, acumen breve, basi inaequalia, acuta vel subobtusa vel obtusa; nervis lateralibus brochidodromatibus, interdum camptodromatibus; paniculis femineis parvis, terminalibus, articulatis, suberoso-rugosis: fructus coccis conchiformibus.

Speceis clari scientisti Paulo de Almeida Machado dedicatum, regenti nostri.

Holotypus - Estrada Manaus-Itacoatiara, $\mathrm{km}$ 155 , no varadouro para a picada XIX, lado direito, leg. W. Rodrigues 9000, em 11-2-1971, INPA 28470.

Possui afinidade com Fagara djalmabatistae Albuq., mas separa-se desta por ser árvore grande, alta, de copa esgalhada e apresentar o pecíolo, peciólulo e página inferior dos folíolos velutinos, inflorescência com ra. mificações articuladas, suberoso-rugosas e cocas maiores.

CARACTERÍSTICAS GERAIS DA MADEIRA

Madeira branco-palha e sedoso-brilhante nos cortes tangencial e radial; moderadamente pesada $\left(0,60 \mathrm{~g} / \mathrm{cm}^{3}\right)$. Grã direiat, textura média, insípida e inodora. Fácil de trabalhar.

\section{DESCRIÇÃO MACROSCÓPICA}

Paiênquima - Contrastado, visivel a ôlho $\mathrm{nu}$, formando faixas contínuas e interrompidas e irreguiarmente espaçadas; raramente aliforme e aparentemente vasicêntrico. Poros - Visíveis a ôlho desarmacio, vazios, solitários, predominantes, geminados e múltiplos de 3 e raramente de 4 . Pequenos a médios $(0,1 \mathrm{~mm}$ a $0,3 \mathrm{~mm}$ de diâmetro); distribuição difusa; poucos a pouco numerosos (3) a. $7 / \mathrm{mm}^{2}$ ). Linhas vasculares - Visíveis mesmo sem lente em linhas retas e às vêzez apre sentando leves sinuosiclades. Raios - Visíveis a ôlho nu os mais largos e sob lente os mais estreitos; numerosos. Na face radial, pouco contrastado com o fundo sedoso, porém visíveis a ôlho nu. Canais secretores e máculas medulares - Não foram observados. Camadas de crescimento - Aparentemente demarcadas por faixas do parênquima terminal e zonas fibrosas mais escuras.

\section{S U M M A R Y}

In this previous note a new species of Rutaceae is proposed. Principal characteristics of the species, and general characteristics and macroscopic description of its wood are presented.

\section{BIBLIOGRAFIA CONSULTADA}

Albuguerque, B. W. P. DE

1968 - Novas Rutaceae da Amazônia. Publ. INPA; Botânica, $27: 15$.

1970 - Uma Nova Espécie de Rutaceae da Amazônia. Publ. INPA; Pesquisas Florestais, Manaus, $8: 1-4$.

- Contrib ação nara "Conhecimento das Fspé. cies Amazônicas do Gênero Fagara (Rutaceae). $\mathrm{Bol}$. INPA; Pesquisas Florestais, Manaus, $13: 1-22$.

ENGLER, A.

1872-1877 - "Rutaceae". In: Martius, C. F. Ph. de, Flora Brasiliensis, Leipzig, Fried. Fleischer, Com. 12(2) : 78-196.

Metcalfe, C. R. \& L. Chalk

1965 - Anatomy of the dicotyledons. Oxtord, Clarendon, $I: 311-313$.

(") Pesquisador do Instituto Nacional de Pesquisas da Amazônia e bolsista do Conselho Nacional de Pesquisas. 